\title{
Uma conversa com Ruy Fausto
}

\section{Paulo Amaral}

Nicolau Spadoni

Universidade de São Paulo

Gostaríamos de agradecer ao prof. Silvio Rosa Filho pela amizade e indispensável ajuda teórica e ao próprio prof. Ruy Fausto pela cordialidade e enorme atenção com que nos concedeu essa entrevista. 


\section{O senhor poderia começar por nos contar um pouco da sua trajetória acadê-} mica, e em especial a sua relação com o departamento de Filosofia da USP?

A história toda é muito longa, você imagina. Alguns traços. A filosofia me veio devagar. É verdade que a "dialética" me bateu na cabeça muito cedo, pela via da política e do marxismo. Mas só a "dialética", isto é, o que eu então entendia por isso. Tive como professor secundário de filosofia o Dante Moreira Leite, que era um psicólogo. Mas através dele, ouvi falar de Heráclito, de Aristóteles, de Descartes, e de alguns outros. Mas eu vivia mesmo era a política. Optei pela filosofia. O curso era muito fraco. Os franceses haviam partido. Outros franceses chegariam, porém, mais para os sociólogos. Para nós também, mas não para os alunos do primeiro ano. A situação do curso era a da filosofia no Brasil. Assim, continuei meio desamparado. Digo, com relação à filosofia. Fui bom aluno, cai nas graças de Cruz Costa e de Lívio Teixeira. Duas figuras excelentes. Ganhei bolsa, fui para a França. Lá assisti as aulas do Goldschmidt e também do Granger, que já conhecera em São Paulo. Eu tinha horror da leitura estrutural, mas, como não poderia deixar de ocorrer, acabei aderindo. Então, aconteceu o pior: fiquei gravemente doente, por conta do inverno e da má alimentação. Uma espécie de pleurite, um mês de hospital. Foi a descida aos infernos. Porque não se sabia bem o que eu tinha: câncer ou o que fosse. Graças ao Granger, pude continuar com a bolsa. Depois fui à Alemanha, fazer um curso no Goethe Institut. Tinha amainado um pouco com a política. Mas 
participara, como tradutor, de um congresso mundial trotskista, isso na passagem do ano, de I960 a I96r. Voltei meio abalado ainda. Não fiz tese (só fui fazer muitos anos depois). Eu escrevia com dificuldade. Traumas da infância. No departamento foi um horror. Quase fui liquidado por uma competição violenta. Quase me matam intelectualmente, e talvez também fisicamente (hoje se sabe que se pode morrer por causa de perseguição, assédio, ou outros horrores dessa ordem). Depois, as coisas foram melhorando, melhorando, com altos e baixos é verdade.

Na "Nota Introdutória" à Lógica e Política: Tomo l', o senhor cita a "experiência na Europa" como marcante para as discussões ali realizadas. Como o senhor mesmo diz em seguida, aquele era um contexto em que se colocava "a exigência e a dificuldade de, ao mesmo tempo, retomar os problemas da dialética clássica (Hegel e Marx) e fazer a crítica da dialética clássica"...

A dialética? Como disse, eu tinha obsessão pela coisa, embora não soubesse bem do que se tratava. Depois, fui fazendo progressos. De tanto tentar ler Hegel, o bicho começou a ter sentido. Eu andava sempre com alguma (má) tradução do Hegel debaixo do braço, mas ficava longe do texto. O que era positivo e negativo ao mesmo tempo. Na mesma época, fui estudando Marx. Longos anos de leitura, em classe ou não. Marx, Hegel, Aristóteles. A teoria do movimento em Aristóteles me serviu muito. Adorno só chegaria mais tarde. Em política, deixei de ser militante. Continuei fã de Trotski e de Lênin, por algum tempo, mas principalmente continuei marxista por mais uma década ou duas. A crítica começou lá pelo final dos anos I970, portanto já há quase quarenta anos. Finalmente, li três livros na vida: A Grande Lógica de Hegel, o Capital de Marx, e a Dialética Negativa

I FAUSTO, Ruy. Marx: Lógica e Política: investigações para uma reconstituição da dialética (tomo I) [MLP I]. São Paulo: Brasiliense, 1983. 
de Adorno. Passei décadas lendo os três livros, e eles foram, e de certo modo ainda são (embora não me considere marxista já há muito), as minhas referências. Meus interesses foram sempre dois: lógica (num sentido bem amplo, aliás o Goldschmidt me apoiaria nisso), e política (também num sentido muito amplo: filosofia da história e política). Esqueci de falar da poesia. Li e leio bastante poesia. De um modo selvagem, é verdade; mas o meu primeiro livro literário - por ora só tenho dois - só viria no século XXI. Também não falei da minha história propriamente pessoal: órfão de mãe aos três anos e meio. Infância e adolescência complicadas. O resto não importa, talvez apenas dizer que sou meio músico amador, medíocre na chamada música "erudita" (que, entretanto aprecio), mas que se vira mais ou menos, na popular. Acho que a música me salvou algumas vezes.

\section{O senhor poderia nos contar mais sobre esse ambiente intelectual francês que você encontrou à época e como sua obra daí surge e nele se insere? \\ Olha, eu acho que não tenho obra, pelo menos por enquanto. Fiz algumas coisas. Só isso.}

Trabalhei em Paris 8, que era a antiga Vincennes. Era um ambiente muito especial. Não era uma faculdade típica. Era de extrema esquerda, com o melhor e o pior. Foucault tinha estado lá, mas já havia saído quando da minha entrada. Mas estavam lá o Deleuze, o Lyotard, o Chatêlet. Havia também militantes, e menos até que isso, havia quem tivesse entrado lá por ser casado com militantes. Eles dividiam os departamentos pelos grupos políticos... Havia bons filósofos franceses, aliás, parte dos melhores filósofos franceses, mas de outro lado, gente absolutamente incompetente. Era uma loucura. Tinha de tudo. Agora, dava para trabalhar. Dava para fazer o que se quisesse. Para começar, você podia simplesmente não aparecer. 
Tinha gente que ia e cantava. Havia debates. Ou você podia ler a Lógica do Hegel. Me disseram que não dava, mas eu passei anos lá fazendo coisas bastante técnicas, e deu certo. Depois os velhos morreram ou foram se aposentando, e chamaram um certo professor que ensinava no Canadá, e que é um carreirista internacional. Aí a coisa se tornou um desastre, carreirismo radical explorando a condição de um departamento de esquerda. Ali eu perdi um pouco o bonde. Uma editora que havia lá na época, a Galilée, me havia proposto publicar apenas um artigo, entre os poucos que eu havia escrito na época, o Humanismo e anti-humanismo. Eles queriam fazer um livrinho. Eu disse que não, pois achava que era um livro muito pequeno e queria fazer um maior. Para isso, levei uns dois anos. Quando eu voltei, tinha vindo uma das ondas da chamada grande crise do marxismo e ninguém publicava mais nada sobre Marx. Eu acabei soltando o primeiro volume do Marx: Lógica e Política numa pequena editora. Inclusive pus algum dinheiro naquilo, o que foi boa ideia, senão não teria saído nada. (Eu havia ganho uma soma considerável com as duas edições brasileiras daquele primeiro volume). Mas se tratava de uma pequena editora. E por várias razões, acabei bastante marginalizado lá. Fui lido por especialistas. Acho que, desse ponto de vista, três coisas me prejudicaram: a condição de estrangeiro, a condição de "dialético" e as minhas complicações de forma. Cada uma dessas coisas não é grave isoladamente, mas as três juntas atrapalham. Eu publiquei três livros lá, mas depois ficou difícil publicar, e eu perdi a vontade de me empenhar nisso. Entretanto, um livro recente e importante sobre Marx se refere bastante ao meu volume, que é dos anos oitenta. 
O senhor faz referência à diversas modalidades de juízo no transcorrer de sua obra². Como que uma certa "teoria do juízo", que emerge em momentos centrais do projeto das Lógicas e Políticas, responde às leituras coupouristas de Althusser (corte epistemológico), Gianotti (corte lógico) e Löwy (corte político)? A teoria do juízo? É algo que tento desenvolver. Que continuo tentando. Falta-me uma base mais sólida em lógica. Mas não creio que seja muito pouco o que consegui fazer. Tenho plano de me associar a algum lógico, com interesse pela dialética, e tentar organizar melhor as idéias. (O outro grande projeto, também pensando num trabalho a quatro mãos, é retomar o projeto de uma crítica da economia política. Projeto megalômano, talvez. Não sei). Quanto aos nomes que você menciona. Althusser está longe de Hegel, embora por vias tortas às vezes perceba algumas coisas, mas que é incapaz de definir. Michael não se ocupa de lógica. É um historiador das idéias. Velho amigo. Sobre Giannotti, difícil dizer. É meu inimigo histórico. Embora a raiva não esteja mais muito viva. Porém esquecer, não esqueço. Mas deixando isso de lado: ele começa bem, mas não creio que tenha continuado muito bem. Talvez seja pretensioso da minha parte, mas, reconhecendo o papel que ele teve em certo momento, acho que ele nunca entendeu direito a dialética, nunca chegou realmente até ai. Embora tenha feito trabalhos úteis e tenha tido certamente um papel. Mas fico por aqui sobre Giannotti. Tenho um longo texto sobre a minha briga com ele. Texto que alguns amigos conhecem. Vou integrar esse texto a uma tentativa autobiográfica, que já comecei não sei quantas vezes, e que deve sair, se eu não morrer antes. De qualquer modo, ficam os fragmentos.

Como essa "teoria do juizo", sobretudo os juizos de reflexão e de devir, se articulam em relação ao humanismo e ao anti-humanismo?

2 FAUSTO, Ruy. Marx: Lógica e Política: investigações para uma reconstituição da dialética (tomo II) [MLP II]. São Paulo: Brasiliense, I987, p. 85-86, nota I32. 
Bom, há uma articulação entre a lógica, e problemas substantivos, como o do humanismo. O meu ensaio sobre humanismo e anti-humanismo representa o momento em que as coisas começaram a se organizar na minha cabeça. Pareceu-me que a filosofia francesa girava numa má dialética transcendental, porque não conhecia os juízos que a lógica dialética conhece. E é isso mesmo. Até hoje, praticamente ninguém comentou esse meu texto na França. E ele saiu (com o MLP I) em francês, em I987. É verdade que Laval e Dardot desenterraram o livro, e estão na pista da distinção posição/ pressuposição. O trabalho deles é sério. Mas estão ainda um pouco longe da dialética. Espero que cheguem lá (é principalmente Dardot, o filósofo da dupla, que se encarrega desse trabalho, mas a contribuição de Laval é também muito séria; os dois se completam).

\section{Retomando um ponto da questão anterior, por que e como você pretende retomar o projeto de uma crítica da economia política?}

Eu andei estudando economia e refletindo sobre o Capital. Indiquei um pouco esses textos, esses caminhos, no meu último artigo para a Piauí3. Aliás, estou convencido de que a crítica que faz O Capital, enquanto tal, não serve mais. Mas, ao mesmo tempo, o Capital é um "livrão", um livro complicado, e muito importante. Mas existem aí, para mim, dois problemas: um é o do tempo de vida, não sei se vou ter tempo para fazer isso, e outro é o da competência. Aí, seria uma possibilidade fazer uma parceria, tentar realizar esse projeto com um economista, que é o que está na minha cabeça. Daria para fazer certas coisas, pelo menos avançar certos tópicos... Eu trabalhei muito o Capital. Se houver um economista heterodo-

3 FAUSTO, Ruy. "Reconstruir a esquerda. Um balanço crítico da experiência histórica e algumas ideias para o futuro" In: Piauí. Número r2ı: out. de 20r6. Disponível em: <http://piaui.folha.uol.com.

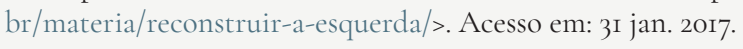


xo com quem eu me entenda bem, pelo menos a gente avança, atravessa o Capital, desmonta certas coisas, recupera... Ainda que não saísse a (nova) Crítica, sairia ao menos um Para uma (nova) crítica... Mas poderia sair muita coisa. Eu trabalhei a vida inteira nisso e tenho uma posição livre em relação a Marx. E os economistas também, no mundo inteiro, começando pelos keynesianos, que são considerados meio ortodoxos (eles são tidos, por aí, como a esquerda da ortodoxia). Mas os keynesianos vão longe na crítica, embora eles conservem as referências aos neoclássicos. Stiglitz, por exemplo, eu leio com muito prazer. Ele dá muita porrada no sistema. E à esquerda (teórica) do Stiglitz tem um monte de coisas também. Claro que também deve haver gente fraca, os vigaristas, os incompetentes, como também há do lado da direita. Mas existe uma discussão mundial e não vejo como nós, filósofos, podemos ficar de fora dela. Você não vai se transformar em economista, mas é preciso ter uma competência grande no assunto. Senão você fica na posição dos que desistem de dizer uma só palavra sobre a economia, porque de economia não entendem. É uma posição válida, mas insuficiente. Acho que teríamos de pensar em fazer colóquios, grupo de estudos, disciplinas, um pouco no modelo daqueles antigos seminários, para trabalhar muito a crítica da economia, isto é, a crítica da realidade econômica e dos neoclássicos. É uma coisa interessantíssima, apaixonante. Tem filosofia de monte por trás disso, e problemas práticos enormes... E aí, entra Hegel no meio, pois há, por exemplo, problemas de fundamentação e de não-fundamentação. 
No artigo Dialética e psicanálise, o senhor se refere ao "juizo de reflexão" como a "proposição especulativa' de Hegel"4 em que a relação central se caracteriza pelo "passar em". Como se definiria, mais precisamente, essa "passagem"? Sua matiz é estritamente hegeliana (ca. Aufhebung) ou há também uma influência de desenvolvimentos posteriores, como do conceito de sublimação de Freud ou da síntese de transição de Husserl?

Não, o meu modelo é dialético mesmo. Hegel e Marx. E depois Adorno. Descobri essas coisas, lendo para valer esses autores. Mas até aqui não consegui dar um forma sistemática à coisa. O melhor está num capítulo no MLP IIIs (melhor do que no livrinho francês Sur le concept de Capital, Idée d'une Logique dialectique ${ }^{6}$. O meu texto sobre a dialética e psicanálise se serve dessas figuras. Espero republicar esse texto em mais algum outro lugar. Li bastante o Husserl, tenho interesse por ele, e de fato em conexão com a lógica dialética. Mas, digamos, por causa da lógica (em sentido amplo), e não da dialética. Isto é, não pretendo tirar dialética de Husserl.

Ainda no artigo Dialética e psicanálise, o senhor parece identificar, na esteira de Kant e Adorno, a liberdade do sujeito como autonomia do mesmo, ou, em suas palavras, "a possibilidade de uma instância do sujeito que não corresponda sem mais ao eu e ao isso modelados pelas exigências externas (servindo-se, parece, das pulsões destrutivas), mas que, pelo contrário, se eleva em alguma medida por sobre essas exigências"7. Nesse sentido, o senhor retoma a leitura de Adorno da psicanálise, dizendo que o verdadeiro projeto de autonomia do eu estaria "em um trabalho sobre a pulsão de morte". O senhor poderia desenvolver um pouco mais os sentidos psicanalítico e ético-filosófico dessa formulação?

4 FAUSTO, Ruy. "Dialética e psicanálise". In: SAFATLE, Vladimir. [org.] Um limite tenso: Lacan entre a filosofia e a psicanálise. São Paulo: Editora da UNESP, 2003, p. I35.

5 FAUSTO, Ruy. "Sobre o conceito de capital. Idéia de uma lógica dialética“. In: Marx: Lógica e Política: investigações para uma reconstituição da dialética (tomo III) [MLP III]. São Paulo: Editora 34, 2002.

6 FAUSTO, Ruy. Sur le concept de Capital. Idée d'une Logique dialectique. Paris: L'Harmattan, I996.

7 FAUSTO, Ruy. "Dialética e psicanálise". Op. cit., p. I37. 
É, vou por aí. Pela leitura que o Adorno faz da psicanálise. Na realidade, a coisa me interessa muito, mas parei com essas leituras - espero que só provisoriamente - porque não dá para fazer tudo ao mesmo tempo. Ou, pior ainda: não dá para fazer tudo. Nos últimos anos, li essencialmente história e economia. E li os jornais. Mas logo que tiver um pouco de folga, volto já estou voltando - a Frankfurt. Quanto à psicanálise, seria triste se não tiver vida para avançar pelo menos um pouco no interior dela. Mas fico devendo a resposta, pelas razões indicadas. Fiz um parêntese nas minhas leituras de psicanálise, e teria que fazer muito esforço para responder à sua pergunta, pelo menos no nível do que escrevi naquele ensaio (a propósito: agradeci a uns e outros, e reitero os agradecimentos, mas as idéias do ensaio, mesmo em psicanálise, são de minha lavra).

Haveria uma "regressão" anti-humanista no ambiente teórico e politico de hoje em dia que estaria fundamentada em uma incompreensão da "passagem do histórico ao transcendental"8, isto é, de uma incompreensão do fato de que uma ética "humanista" seria algo que teria se constituido no curso da história?

Há ou houve uma moda anti-humanista. A dos Žižek, Badiou e cia. Tudo muito fraco. Muito medíocre, apesar dos ares de grande teoria. Hoje acho que isso arrefeceu um pouco. Há é uma grande confusão. Política e teórica. É preciso retomar o fio dos problemas, nos dois planos. Há uma articulação complexa entre o histórico e o transcendental. Acho que a reflexão do Adorno gira em grande parte em torno disso.

De um ponto de vista histórico, o senhor tem insistido na revisão critica das

8 Cf. FAUSTO, Ruy. A ofensiva teórica anti-humanista. Em torno das teses de Alain Badiou e Slavoj Žižek. Fevereiro: Política, Teoria, Cultura, 20Io. Disponível em: <www.revistafevereiro.com/ pag.php?r=OI\&amp; t=OI>. Acesso em: 3I jan. 2017. 
revoluções do século XX9 ${ }^{9}$, destacando, em especial, a Revolução de Fevereiro de 1917 em detrimento da Revolução de Outubro e seus desdobramentos. Em Lenin, Outubro: o discreto charme da ortodoxia ${ }^{10}$, o senhor fala mesmo de uma "grande regressão histórica" entre Fevereiro e Outubro que, inclusive, parece refletir uma própria guinada anti-humanista do movimento. Essa análise é feita contra autores como Žižek, para quem haveria, apesar dos fatos históricos, uma "grandeza ideal" na Revolução de Outubro, no "significante Lenin" e em seus desdobramentos. Como o senhor vê, portanto, o nexo entre lógica e a autonomia do objeto histórico?

Vocês dão um salto grande demais com a frase final.

Sobre a história contemporânea, há que repensar tudo. A chamada revolução de outubro, e a também chamada revolução chinesa. A primeira foi uma espécie de golpe, sobre o fundo de uma revolução que eles "completaram“, isto é, liquidaram. A outra foi um longo processo revolucionário, que levou ao poder não os camponeses, mas uma burocracia de pequenos letrados. Se esta não levou os camponeses ao poder, a outra não levou o proletariado ao poder. Vive-se dessas duas ilusões. Uma confusão absoluta. O que não significa que os efeitos não tenham sido enormes nos dois casos. Mas efeitos enormes não significam bons efeitos. Embaralha-se isso tudo. Confunde-se o que é importante historicamente com o que representa real progresso, ou é eticamente justo. No Brasil, principalmente, a confusão é geral.

Em seu último artigo, o Galo e a Coruja: A propósito de Para a Critica da Filosofia do Direito de Hegel (Introdução) (1844) ${ }^{11}$, o senhor nos lembra como

9 Cf. FAUSTO, Ruy. "Para um balanço crítico das revoluções le de alguns movimentos de reforma] do século XX (A esquerda onde está?)". In: A esquerda difícil. São Paulo: Perspectiva, 2007. io FAUSTO, Ruy. "Lenin, Outubro: o discreto charme da ortodoxia". In: A esquerda difícil. São Paulo: Perspectiva, 2007. p. I74.

i FAUSTO, Ruy. O galo e a coruja: a propósito de Para a Crítica da Filosofia do Direito de Hegel (In- 
o texto do jovem Marx traz à tona um tripé conceitual fundado nos termos "crítica", "emancipação" e "revolução", que se alternam não só na própria obra marxista, como também no decorrer dos acontecimentos do século XX. Como o senhor enxerga o sentido da "crítica" nos tempos de hoje, em especial em sua relação com "revolução" e "emancipação"?

Hesitei muito em relação ao termo "revolução". Talvez seja o caso de conservá-lo. "Emancipação" é muito bom. "Critica" é indispensável. "Emancipação" é uma palavra dos frankfurtianos. É a ideia de uma sociedade livre, liberada. Uma sociedade com o máximo de liberdade e com o máximo de igualdade. O ideal não é uma igualdade absoluta. O problema não é terminológico, embora, como se saiba, a questão dos nomes está longe de ser insignificante. Seria preciso investir muito mais seriamente em tudo isso. O atraso é visível. Principalmente no Brasil.

O senhor utiliza o termo "apresentação da história" em Marx para designar três modelos de exposição da história (da liberdade no Manifesto Comunista e Ideologia Alemã, da riqueza nos Grundrisse e em O Capital, e da satisfação nos Manuscritos Econômico-Filosóficos de 1844), e não uma filosofia e teoria da história unificadora ou totalizadora (como estaria presente em Marx, segundo certas leituras de Lefort e Castoriadis), lançando mão, para tanto, da sua proposta de silogismo dialético ${ }^{12}$ presente na Lógica do Conceito de Hegel para marcar a diferença entre as distintas exposições marxistas da história. O senhor poderia nos explicar mais detalhadamente a sua leitura dessas exposições da história e as diferenças em relação às leituras de Castoriadis e Lefort?

A primeira coisa (questão de história do pensamento, mas importante) é bem identificar a melhor leitura da história que se pode tirar de Marx (ele tem versões melhores e piores). A boa é a leitura descontinuísta (ou antes, conti-

trodução)(1844), de Marx, e de algumas dificuldades originárias do projeto marxiano. Curitiba/São Carlos: Dois Pontos, vol. I3, no. I, p. 3-28, 2016.

I2 FAUSTO, Ruy. MLP III, p. iा8. 
nuísta e descontinuísta). Ver principalmente MLP II ${ }^{13}$. Os franceses, mesmo os melhores, ainda não chegaram até aí. Mas para além do problema (finalmente secundário, de saber o que Marx pensava ou que se pode encontrar em Marx), temos que refletir sobre a historia, e aí estou muito inclinado a propor um esquema que é, de um certo modo, cíclico. Ver o meu artigo "Reconstruir a esquerda”, publicado pela Piauí, em outubro de 2016. Volto a isso em outros textos, atualmente no prelo. O miolo do primeiro texto desse livro é um pouco a crítica de Benjamin. Ou uma espécie de radicalização das Teses de Benjamin. Este critica a social-democracia e o continuísmo histórico dos reformistas, mas não critica o bolchevismo, e as ilusões históricas dos comunistas (fora vagas alusões). E todo mundo repete o que ele escreveu, em lugar de repensar tudo. Com isso, evidentemente, não estou querendo jogar fora o Benjamin.

Quanto a Lefort e Castoriadis: gosto da obra dos dois. Mas o último Lefort é um pouco decepcionante. Como ele próprio reconhece, ele nunca resolveu o problema da relação capitalismo e democracia. (Na realidade, da "economia de mercado" e democracia: o outro problema não tem solução). Quanto ao Castoriadis, cuja obra é notável, diria que ele tem certas insuficiências, digamos, tanto no plano teórico como no plano político. A crítica que ele faz ao Marx é justa em grandes linhas, mas só em grandes linhas. Castoriadis não entende de dialética. O que não é grave. Nem só de dialética vive o mundo. Mas isso limita um pouco o seu alcance teórico. Politicamente, ele é um pouco vago no que se refere aos caminhos das lutas emancipatórias, e acho que simplifica bastante o problema do poder. Em todo caso, junto com Adorno, a dupla Castoriadis e Lefort - cada um a seu modo - são as duas referências mais importantes.

i3 FAUSTO, Ruy. "Para uma crítica da apresentação marxista da História: sobre a sucessão dos modos de produção". In: MLP II. 
No seu texto "Esquerda/direita: em busca dos fundamentos e reflexões críticas $^{114}$, publicado na Revista Fevereiro, o senhor retoma a antiga questão "Reforma ou Revolução" para explicitar qual seria uma posição coerente da esquerda, levando em consideração também a atual forma de nossa democracia e do capitalismo. O senhor poderia nos explicar melhor como seriam (ou deveriam ser) as posições para tal esquerda hoje (o que deve ser retomado como fundamento, do que não se pode abrir mão, o que deve ser deixado de lado etc.), em especial ao considerarmos os "erros" históricos do século $X X$ ?

Acho que é preciso ligar duas coisas que se costuma considerar como antitéticas: a exigência democrática e o ideário anti-capitalista. Supõe-se que os dois têm soma nula. O que acontece de fato. Mas não de direito. É preciso reafirmar a exigência democrática. E isso por várias razões. Sem ela, por exemplo, nem se entende a história dos séculos XX e XXI. Mas, ao mesmo tempo, importa retomar a crítica do capitalismo. E aí há muita novidade. Na minha opinião, é preciso cruzar Marx com o socialismo dito pequeno-burguês (Sismondi, Hodgskin, Leroux, Proudhon, etc.). Eu acho que Marx erra. Ele queria ditadura do proletariado, comunismo, e acho que isso está errado. Sociedade transparente não dá. Agora, Marx era moderno. O mal dele é que ele era mais ou menos prometeano. Mas já aquela turma [do socialismo "pequeno-burguês"] tinha o grande mérito de querer manter mercado e dinheiro. Acho que tudo isso é válido. E, principalmente, manter democracia. Agora, também não dá pra jogar todas as cartas neles. A verdade é que, mesmo se isto pode parecer uma banalidade, a gente precisa do conjunto da tradição socialista e comunista do século

i4 FAUSTO, Ruy. "Esquerda/direita: em busca dos fundamentos e reflexões críticas". In: Fevereiro: Política, Teoria, Cultura, outubro de 20I2. Disponível em: <www.revistafevereiro.com/pag. php? $\mathrm{r}=05$ \&t=I3>. Acesso em: 3r jan. 2017 . 
XIX. Marx sempre levou a sério as experiências cooperativistas, mas ele achava que não funcionava, e ao dizer isso tinha suas razões. De qualquer forma, é tudo muito complicado. Proudhon era um sujeito antipático. Era misógino, antissemita... Mas tem méritos, pelo medo que ele tinha do Estado, pelo fato de querer, no fundo, conservar a propriedade, apesar de ter ficado famoso pela sua crítica a ela. Tem também o Leroux, que é curioso. Era um socialista meio cristão e que tinha muito medo de ditadura revolucionária. Há Sismondi, um economista crítico suíço... Tem também o livro do Bray, Labor's wrongs and labor's remedy ${ }^{15}$, um livro um pouco tardio nessa tradição. É um livro muito bem escrito. Eu andei espiando e é bom, fala de formas cooperativas... Vários desses autores foram reeditados, alguns em fac-símile do texto original. Há uma chusma de neosmithianos, sendo o mais famoso deles o Hodgskin. Eles querem, mais ou menos, o esquema de circulação simples, mas não o capital. Isto é, querem brecar o movimento de passagem de uma para o outro. Depois de tudo o que aconteceu, eu acho que a gente é obrigado a jogar um pouco nos neosmithianos. Estes socialistas estão todos lá no capítulo das Teorias da mais-valia em que Marx polemiza contra os economistas. Marx é injusto com relação ao Sismondi; é mais justo em relação à essa turma [dos neosmithianos]. Mas tudo faz parte de uma vasta literatura crítica. Marx se alimenta disso tudo e sai com a teoria crítica dele, para melhor ou para pior. Ele leu toda a literatura econômica da época, tinha uma paixão teórica violenta. Ele é muito mais forte que os outros, mas isso não quer dizer que ele acerte mais por isso e nem que, em termos de teoria, ele não possa errar também. Enfim, teríamos que ver o que fazer com aquele "livrão". Mas Marx achava que a simples economia de mercado dava necessariamente em capitalismo, en-

I5 BRAY, John Francis. Labour's Wrongs and Labour's Remedy: or, the Age of Might and the Age of Right. Read Book, 20I. 
tão no longo prazo se tratava de acabar com mercado, com dinheiro, e instaurar a comuna. Eu acho que isso não dá, e aí é preciso distinguir os dois caminhos. E escolher o que Marx não escolheu.

A isso se acrescenta o problema ecológico. De um certo modo é o fundamental. Mas só de um certo modo. Há uma tendência a diluir a oposição esquerda/direita, e em geral os problemas propriamente políticos, no discurso ecológico. Isso é uma ilusão propriamente desastrosa. A ecologia, fundamento ou não, tem de enriquecer a reflexão e a luta no plano econômico-político. Mesmo porque as duas coisas estão ligadas: a crise econômica provoca a vitória de Trump, que põe fogo no mundo. Basta essa referência para ver a bobice dos que pensam que a ecologia transformou a política em jogo infantil no interior do grande cosmos. Outra coisa: não entendo ecologia sem crítica do nuclear. Pois, infelizmente, isso também existe.

Uma questão central para a compreensão de suas posições lógicas e políticas parece residir no seu entendimento do capitalismo. $O$ senhor poderia discorrer sobre o que entende por uma "ideia do modo de produção capitalista" e os limites/possibilidades/insuficiências desta para "definir o capitalismo na sua forma dominante atual" ou, mais além, para se pensar uma teoria das formas sociais ${ }^{16}$ ?

É um assunto que exige uma conversa comprida, evidentemente. O modo de produção capitalista deve ser definido pela política, também. A sociedade atual é a de um capitalismo liberal ou mesmo, se pode dizer, de um capitalismo democrático, mas é preciso ressaltar que há ai uma contradição. Contradição objetiva. Mas acho que é necessário incluir a forma política, sempre, senão não se entende nem se pensa o objeto. Os marxistas

i6 FAUSTO, Ruy. MLP III, p. i7-I9. 
dizem: é capitalismo, os liberais dizem: é democracia. São as duas coisas. Eu diria que não basta falar em "modos de produção". Deveríamos tomar como conceito não "modo de produção", mas "modo de poder e de produção". Deixando claro que, numa mesma formação, pode haver um modo de poder que não é rigorosamente congruente com o modo de produção, ou só o é dentro de certos limites (ou, de fato, não de direito).

Além disso, vivemos um tipo particular de capitalismo. Com privilégio do capital financeiro. E muitas vantagens para os mais ociosos. Muita desigualdade também, e desemprego. E aí há muita história, também, que afinal creio que não se estudou o suficiente. Como é que acabaram os Trinta Anos Gloriosos? Como é que termina o tempo do welfare? Isso tudo é para se estudar (mesmo se, claro, tem bibliografia, e boa, a respeito). É coisa para economista, mas para filósofo também.

Vamos para o abismo? Não sei. Mas a vitória de Trump talvez anuncie um grande movimento em direção ao buraco. Uma nova rodada do tipo da que o mundo teve nos anos i930? Vamos ver. Menos violenta, aparentemente, no plano político. Mas com complicações no plano ambiental, precisamente. Então pode vir um estouro comparável em violência ao do nazismo, mas que nascerá de um outro pavio (embora as condições sejam globalmente parecidas).

O senhor inicia o Lógica e Política: Tomo I afirmando que aquela seria a primeira parte de cinco previstas. Por outro lado, em Lógica e Politica: Tomo III, o senhor observa, sobre a obra marxista, que "o saber marxista é ao mesmo tempo aquele que está mais rigorosamente imerso no tempo da história concreta, e o que toma o máximo de distância em relação a esta história enquanto história vivida, e, por paradoxal que isto possa parecer, também 
enquanto práxis" ${ }^{17}$, o que parece determinar a distancia entre o tempo vivido e o tempo do conceito. Tendo em conta estas duas posições, é possivel afirmar uma arquitetônica das Lógicas e Políticas? Como ela se dá (sobretudo se notarmos as observações que o senhor mesmo faz na citada obra em relação às distintas considerações sobre os textos de Trotsky ou Lenin, ou seja, antes e depois de o senhor enfrentar o "problema do bolchevismo"18? Tal arquitetônica mudou ou seu projeto original se mantém? De que modo a pesquisa se deslocou no meio do caminho?

O projeto foi mudando. Mas, no fundo, não mudou tanto. A novidade é que fui ficando crítico em relação ao marxismo. Bom, quando era jovem, muito cedo, pus na cabeça a ideia que escreveria um livro chamado "Marxismo e Filosofia". Eu o concebia, pelo menos numa certa fase, em termos de uma oposição: o marxismo não seria uma filosofia. Mas a coisa variou. Tenho a impressão, aliás, de que quando surgiu não era assim tão anti-filosófica. Depois ficou. Depois voltou a ser filosofante. Quando à organização dos tomos. Havia por um lado a crítica ao Althusser (que me estimulou muito, digo, a crítica, mas, com isso, sem dúvida, o próprio Althusser, mesmo se em forma negativa) - não foi aliás só o meu caso. Nesse trabalho, havia a questão do humanismo e do anti-humanismo, que era a mais importante. E um desenvolvimento paralelo sobre o chamado "historicismo". Mas nesse último caso cabem esclarecimentos sobre a noção. Entretanto, havia coisas boas também nesse segundo desenvolvimento (embora o meu texto fosse marxista e até leninista, o que teve de ser criticado e desmistificado). Junto com isso, fui desenvolvendo o problema da dialética. Ou antes, a dialética estava embutida nisso. Mas o tema foi se tomando mais autônomo. Ao mesmo tempo, eu desenvolvia uma espécie de teoria da história, a partir do "melhor Marx", mas tomando distância

I7 FAUSTO, Ruy. MLP III, p. 255.

I8 FAUSTO, Ruy. MLP III, p. 229. 
também em relação a ele. Me permiti discutir temas substantivos: classe, Estado. Havia na origem um esboço sobre as "necessidades". - Escrevi três volumes. Penso em escrever mais dois. Em parte, reunindo coisas já publicadas. Em parte não. O último seria um pouco o "meu livro". Isto se tiver vida suficiente para escrever isso tudo. Mas o volume IV (que reúne, em parte, coisas já publicadas), está praticamente pronto. Falta obter licença para republicar dois textos que saíram em livros (um deles coletivo).

Por fim, dada a sua experiência com ensino e prática da Filosofia, como o senhor enxerga a diferença entre os departamentos de Filosofia no Brasil e na França ou, de modo mais geral, do papel relegado à Filosofia e à figura do filósofo em cada lugar?

Minha experiência é pequena, apesar das aparências. Nunca fui bom professor. A rigor, nunca fui professor. Tive alguns bons momentos ensinando, mas essencialmente quando falava do que hoje se chama das próprias "pesquisas" (no meu tempo, ninguém usava esse termo, para a filosofia). E quando trabalhava em seminário. Minha experiência de seminário a quatro mãos com meu amigo Cicero Araújo foi o melhor que fiz como professor. Mas é que não se tratava exatamente de trabalho de "professor". Quanto aos departamentos, também é difícil julgar: trabalhei em Paris 8, a antiga Vincennes, que era uma Universidade, e um departamento de filosofia, totalmente atípicos. (Mais tarde aquele departamento caiu na mão de um bando de carreiristas, e carreiristas medíocres, o que é mais grave). O de São Paulo é bom. Mas meio acadêmico. Em geral, com os defeitos dos departamentos de Filosofia, e da Universidade. Não se forma espíritos críticos na Universidade. É mais ou menos inevitável talvez, mas é assim. O pessoal, em filosofia, aprende a ler. O que é bom, e é muito. Mas pensar criticamente, nada. À filosofia (ou à sociologia) universitária 
se soma então a preferência por tal ou tal partido. Também daí não vem crítica nem espírito crítico. Este fica entre os dois, talvez sintetize os dois, mas prefiro dizer que fica entre eles, não é nem um nem outro. Eu andei lutando para que esse espírito se desenvolvesse. Estive na origem (junto com outros, evidentemente) do lançamento de pelo menos duas revistas politico-teóricas. Acho que as duas foram (ou são) úteis. Mas esse trabalho é muito difícil. E os perigos estão lá: de um lado a Universidade, de outro os partidos. Para fazer revistas político-teóricas independentes (de esquerda), é preciso pôr entre parênteses (sem jogar fora) tanto a Universidade (filosofia, sociologia, ciência política, o que for), como os partidos de esquerda à la mode. Trabalho difícil, eu disse, mas talvez o mais importante (pelo menos é o que dá para fazer). Porque, se ele é importante em geral, ele o é duplamente para o Brasil. No Brasil, a confusão e a ignorância em matéria de política são a regra. A lucidez é rara. Mas ela existe, pelo menos como possibilidade. Há que contribuir para que ela se desenvolva. 